Proceedings

\title{
Ecosystem vulnerability due to urban growth policies. The role of regulatory ecosystem contributions in the land use planning
}

\author{
Rafael Córdoba Hernández ${ }^{1}$ and Lucas Martí Guitera ${ }^{2}$

1 Departamento de Urbanística y Ordenación del Territorio. Escuela Técnica Superior de Arquitectura. Universidad Politécnica de Madrid. UN-Habitat Planners for Climate Action (P4CA). rafael.cordoba@upm.es

2 Escuela Técnica Superior de Arquitectura. Universidad Politécnica de Madrid; lucas.marti.guitera@alumnos.upm.es

\begin{abstract}
If we understand regional resilience as the ease with which different regions adapt to overcome externally produced crises, it appears as necessary to protect both ecosystems and its services, considering the position these hold in regional planning. To be able to protect and/or preserve these ecosystems, it is of paramount importance to identify the areas most vulnerable to these concerns. It has been necessary to develop a methodology to identify Ecosystemic Vulnerability associated to ecosystemic service loss, aiming to prevent its degradation by correctly protecting or preserving it through regional planning. This should help to establish pressure-mitigating policies which could result in variations in its resilience ability.
\end{abstract}

Keywords: Resilience; ecosystem services; territory; ecosystem vulnerability
Today, the importance of ecosystems and ecosystemic services has general recognition, the problem of their management and degradation being mentioned in the Sustainable Development Goals. It is difficult to assess the various impacts, pressures, and tendencies for each ecosystem, but we do know that the combined impact of all these pressures during long periods of time ends up affecting not only the severity and scope of changes in the ecosystem, but also its capacity to provide services to humankind and its habitat.

In the frame of the recently approved Estrategia Nacional de Infraestructura Verde y de la Conectividad y Restauración Ecológicas [1] (National Green Infrastructure, Connectivity and Ecological Restoration Strategy) this research aims to identify the different ecosystemic services (provision, regulation and culture related) defined by the Common International Classification of Ecosystem Services o CICES [2]. This is tightly related to the recommendations of the European Environment Agency, which delegates the integration of results of an ecosystemic service assessment into territorial planning due to its capacity to identify areas of high and very high ecosystemic service capability [3].

In this context, the hypothesis of this research is that, responding to the territorial ecosystemic values identified, a map could be elaborated, showing the different ecosystems and the services they provide, serving as a possible justification of the protection of those areas with the tools the active legislation on the land (of Spain, obviously) grants the professional planner.

\section{Approaching the territory of study to analyze its ecosystems}

The Community of Madrid is defined, in what regards the planning situation, by the absence of an integral territorial planning, the inadequacy of municipal planning to the actual legislation and an environmental sectorial legislation that could be used to achieve

8


a better territorial sustainability [4], [5]. Environmentally, the region has 8 ecosystems if 1 we follow the habitat classification of the European Nature Information System (EUNIS) [6] differentiating surface waters; wetlands; pastures, grasslands, mosses and lichens; heath, bush and tundra; forests, understories and woodlands; habitats with scarce or no vegetation; farmlands and gardens; and artificial, industrial and other habitats.

This mapping allows the planner to know the distribution and importance in the territory of each service, as the existing ecosystems receive values for each possible service. This value refers to a scale of four (does not apply, low, medium and high) so as to facilitate the understanding of the spatial distribution of each ecosystemic service, as the Guía práctica para la integración de los servicios de los ecosistemas en la formulación de planes y programas territoriales y urbanísticos [7] recommends. This tool not only identifies and limits the extension of different ecosystems by the spatial integration of qualitative data on land cover and its environmental characteristics, but also seeks to increase its preservation, evaluates its state, analyzing the main pressures and relations between its conditions, quality, and biodiversity, and how does that affect the ecosystem's ability to provide its services. This mapping can be obtained both independently, attending to each ecosystemic service alone, and by trying to take into consideration every service. With this result, we can now identify the consequences for humankind and its wellbeing. The importance of these questions is such, that planners must not stay aside and should participate by devising the future uses of these areas, not only valuing them for their natural and landscaping values, but also attending to their ecosystemic services.

In the case of the provision service, we can identify up to five different services. Food provision is clearly recognizable in pastures from which cattle grazes or in crop fields. In other ecosystems, as heaths and lavender fields, it is more difficult to identify the service. However, in the Iberian plateau, these ecosystems are the ones that provide the highest amount of honey, for example. Another contribution is drinking water. Besides those ecosystems that provide water directly, we have considered those that participate positively in the filtration of water towards aquifers, like pastures, forests, or heaths. In this sense, we note that urban parks, well managed, could be a greater vector of water purification. Other services would also be those of raw materials, food production and genetic diversity. In the province of study, the areas with scarce vegetation acquired their value thanks to the steppes in the southeast of the province, incredibly rich in endemisms within their inhospitable gypsum fields, making its value obvious in what genetic regards. Finally, we have considered the services that could be attributable to natural medicine, valued as the possible presence of the plants and bushes common in this traditional practice.

The compound of regulation services is, obviously, the broadest one. Amongst its services is included that of habitat maintenance. To be able to value it, we have considered each ecosystem's biodiversity, if the higher the number of present species, the higher the number of habitats contained. We would like to emphasize the inclusion of crop fields as high value areas, the reason being that in regions as transformed by humans as the plateau, where great unspoiled grasslands are scarce or nonexistent, crop fields, especially when well-managed, stand out as a wonderful habitat for many species of birds, from birds of prey to partridges or even bustards. Moreover, with the adequate management policies, the margins between fields can become astounding biodiversity corridors, accumulating along their borders numerous bushes and trees that shelter birds and rodents.

As climatic service we have considered the different values of carbon sequestration of each ecosystem, being the aquatic ones the most adequate thanks to the presence of algae and microorganisms able to capture carbon dioxide. Their aptitude to serve as cushion for high temperatures has been considered as an independent value. The service of soil fertilization and flood prevention were also analyzed. The presence of vegetation has been considered as favorable to the filtration capacity of an area and minimizes the possibility of a flood event. The conservation of endemic species service is of notable importance. This service can be somewhat controverted due to the inclusion of crop fields (we have already mentioned its relation to birds) and, mainly, due to the inclusion of 
"areas with scarce vegetation". As we have said before, gypsum steppes have, it is true, 1 few visible plants, but an astoundingly rich number of endemic species. As an example, we could mention the Cynerea tournefortii, a kind of huge endemic thistle, normally present in crop fields. Modern day agricultural techniques hinder its growth, and we can find it today mainly in bare lands of southeastern Madrid. These bare land ecosystems are interesting, as any ecosystem is not a static entity, and as such, vegetal succession is an inescapable part of its development. Following this logic, bare lands hold pioneer species that will not appear later when the area takes the form of, for example, a forest. This necessity of allowing the flow of natural cycles is close to the idea expressed before about floods, and letting these events occur when they cannot harm us is of paramount importance to ensure their health. When we talk about soil production, we want to refer to an active gain or creation of centimeters of soil, independently of its richness of nutrients. These different ecosystems were also valued about their capacity to capture carbon dioxide or to filter air (air quality), the participation of each ecosystem in the regulation of the water cycle, the politization cycle, or the presence of birds, rodents and insects that act as pest controllers (where crop fields once more stand out as a possible ground to fulfill this role admirably). Finally, we also valued the role of every ecosystem in preventing erosion and diminishing environmental noise.

Cultural services were integrated by those such as scientific knowledge, environmental awareness, education, or traditional knowledge. Other services would be recreational services, landscape enjoyment (sadly conditioned by aesthetic prejudices) or cultural identity and spiritual inspiration.

Once every service has been valued, we can obtain a territorial assessment of each ecosystemic service, as well as a final synthesis of the total value of each ecosystem. As a result, we obtained that more than half of the region has high ecosystemic service value (434.007 Ha, equal to approximately $54 \%$ of the region).

\section{Conclusion}

The resulting cartography identifies several services that can help justify the preservation of some areas in the Community of Madrid, thanks to the special protection allowed by the active land use legislation in the province, where it states that protections can be issued for determined areas attending to their agricultural, forest, or natural values, which are all tightly intertwined with the ecosystemic services provided by the area.

Showing side to side both the precedent considerations and the active planning in each municipality, we can identify those areas that, being particularly sensitive to the effects of various actions on biodiversity, have a lack of adequate protection from urban and territorial planning, allowing for its partial or global destruction. This information about pressure on certain ecosystems can help evaluate its capability of providing services, design adequate policies to diminish the pressure we put on the environment or even help prevent points of no return that, once crossed, result in a radical change of the ecosystem. In this sense, some $239.513 \mathrm{Ha}$ are fit for urbanization in the Community of Madrid (almost $30 \%$ of the total surface), not considering the ecosystemic services provided by these spaces.

The areas with the highest values are also the most menaced and a more intense concentration can be appreciated towards the west, so to say, the Central System, and towards the Southeast, so to say, the valleys of the rivers Jarama and Tajo.

Of these high-value areas, the $44.706 \mathrm{Ha}$. are considered fit for urbanization as stated in the planning of each municipality, meaning, obviously, the disappearance of the ecosystems and their functions. This is equivalent to $34,0 \%$ of the land planned for growth within the Community of Madrid. 


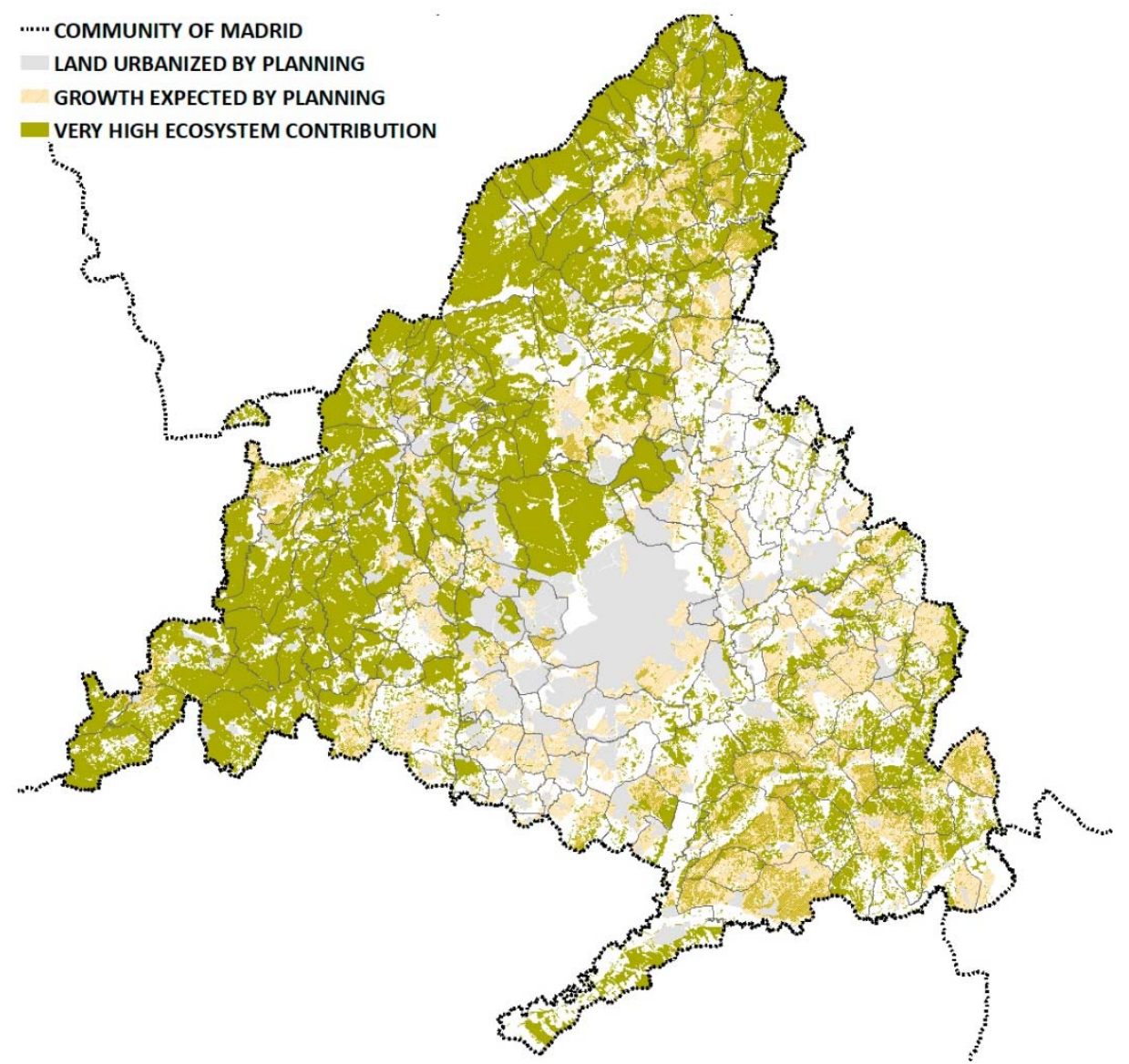

Figure 1. Comparison of the areas with highest value of ecosystemic services and the areas fit for urbanization as stated in the planning of each municipality. Source: Estructura territorial resiliente: análisis y formalización a través del planeamiento urbanístico [8].

\section{References}

[1] Estado Español, “Orden PCM/735/2021, de 9 de julio, por la que se aprueba la Estrategia Nacional de Infraestructura Verde y de la Conectividad y Restauración Ecológicas," Boletín Of. del Estado, no. 166, de 13 de julio, pp. 83217-83470, 2021, [Online]. Available: https://www.boe.es/eli/es/o/2021/07/09/pcm735.

[2] United Nations, System of Environmental-Economic Accounting 2012. United Nations, 2017.

[3] European Environment Agency, "Spatial analysis of green infrastructure in Europe," 2014. [Online]. Available: http://www.eea.europa.eu/highlights/new-mapping-method-for-

2018green\%0Ahttp://www.eea.europa.eu/publications/spatial-analysis-of-green-infrastructure.

[4] E. de Santiago Rodríguez, “Madrid, 'ciudad única': pautas y lógicas espaciales en la región madrileña: las grandes trasnformaciones estructurales; el despliegue del nuevo 'paradigma único' en la región urbana de Madrid," Urban, no. 12, pp. 8-33, 2007.

[5] R. Córdoba Hernández and D. Morcillo Álvarez, "Marco territorial de la producción de espacio en la región funcional de Madrid," Ciudades, no. 23, pp. 71-93, May 2020, doi: 10.24197/CIUDADES.23.2020.71-93.

[6] C. E. Davies, D. Moss, and M. O. Hill, “EUNIS Habitat Classification Revised 2004,” Technology, no. October, p. 310, 2004, [Online]. Available: https://www.eea.europa.eu/data-and-maps/data/eunis-habitat-classification.

[7] B. Fernández de Manuel, L. Peña, I. Ametzaga, and M. Onaindia, Guía práctica para la integración de los servicios de los ecosistemas en la formulación de planes y programas territoriales y urbanísticos, Universida. 2020.

[8] R. Córdoba Hernández, "Estructura territorial resiliente: análisis y formalización a través del planeamiento urbanístico," Universidad Politécnica de Madrid, 2021. 